\title{
Using corpus methodology for semantic and pragmatic analyses: What can corpora tell us about the linguistic expression of emotions?
}

ULRIKE OSTER*

Abstract

The aim of this paper is to explore some of the possibilities, advantages and difficulties of corpus-based analyses of semantic and pragmatic aspects of language in one particular field, namely the linguistic expression of emotion concepts. For this purpose, a methodological procedure is proposed and an exemplary analysis of the emotion concept "fear" in English is performed. The procedure combines Kövecses' lexical approach and Stefanowitsch's metaphorical pattern analysis with additional concepts from corpus linguistics such as semantic preference and semantic prosody. The results of the study show that such a corpus-based analysis of emotion words offers several advantages. Firstly, by exploring the surroundings of the search word in a vast amount of text, we are not only able to find evidence of conceptual metaphor and metonymy that structure the emotion concept and of related emotion concepts, but also we can enrich the description of the emotion concept with information from a series of dimensions and add a pragmatic viewpoint by revealing an explicit or implicit evaluation of the emotion. The second advantage offered by a corpus-based approach lies in the possibility of quantifying results, i.e., comparing the frequency, productivity and creative use of individual metaphors and metonymies, which is especially interesting in view of contrastive studies.

* Address for correspondence: Departament de Traducció i Comunicació, Universitat Jaume I, Campus del Riu Sec, 12071 Castelló, Spain. Email: oster@trad.uji.es. Acknowledgements: I am grateful to two anonymous reviewers for their constructive criticism of an earlier version of this paper, and would also like to thank Heike van Lawick for assisting me with the analysis of metaphorical expressions, and José Luis Martí and Ignasi Navarro for their helpful comments on statistical analysis and prepositional constructions. The study has been supported by research project FFI2009-09544, funded by the Spanish Ministry for Science and Innovation (MICINN). 
Keywords: Emotion concepts, corpus methodology, conceptual metaphor, conceptual metonymy, semantic preference, semantic prosody

\section{Introduction}

Corpus linguistics has grown over recent decades into a well-established field of research, and its methods are now being increasingly applied also in cognitive linguistics. Present-day corpora contain very large quantities of data and are thus especially useful for quantitative studies of grammatical aspects of language, which are more easily analysed through (semi)-automatic search processes than semantic or pragmatic issues. Nevertheless, corpus linguistics has also developed a number of conceptual tools - for example co-occurrence and collocation, semantic preference and semantic prosody - that help to pinpoint semantic and pragmatic aspects of lexical units. The main objective of this paper is to apply these tools to one of the central themes of cognitive linguistic research: the linguistic expression of emotions and their conceptualization through conceptual metaphor and metonymy.

In this field, Kövecses (2005: 32) distinguishes between cognitivelyoriented studies, which typically use elicited data, and language-use-oriented researchers, who tend to use corpus data. The first follow a top-down approach that is directed at a supraindividual level and aim to propose conceptual metaphors on the basis of linguistic expressions. The goal of bottom-up corpusbased studies, on the other hand, is the systematic identification of linguistic metaphors in natural discourse (Kövecses 2008a: 169). These aims and methods can be considered as complementary (Kövecses 2008a: 181-182), and thus the question pursued in this paper is in which way a qualitative approach can be complemented by using quantitative data from electronic text corpora. In particular, the questions that will be addressed are the following: How can corpus-linguistic concepts be applied in order to establish the conceptual metaphors and metonymies that structure our understanding of emotions? Do they reveal additional semantic or pragmatic facets of the words expressing these emotions? How does this methodology differ from other ways of analysing emotion concepts? In what way might these differences influence obtainable results? In order to answer these questions, a method for studying emotion concepts with the help of electronic corpora is proposed and an exemplary analysis of the emotion concept "fear"1 in English is performed.

1. For the sake of clarity, concepts will be marked by inverted commas ("pride"), lexical units used as search words by single inverted commas ('pride'), and co-occurrences from the corpus by italics (heart). 


\section{Corpus-based analyses of the linguistic expression of emotions: A methodological proposal}

\subsection{Background: Linguistic approaches to the study of emotions}

The interdisciplinary field of language and emotion has been the subject of numerous studies in the fields of psychology and anthropology (cf. Wilce 2009: Ch. 2 and 9). Within linguistics, interest in the interrelation between language and emotions is more recent and sometimes still seen as neglected (e.g., Schwarz-Friesel 2007). However, a series of approaches has been developed from different linguistic perspectives (cf. Bednarek 2008a: 6-12 for an overview), and especially in recent years a number of international conferences and theme sessions as well as specific publications on the subject (e.g., Fussell 2002, Schwarz-Friesel 2007, Bednarek 2008a, to name but a few) show a renewed interest in the study of emotion language. For the purpose of this work, I shall briefly overview three of the main methodological approaches used in this area.

Within the framework of natural semantic metalanguage (NSM), emotions are described through a metalanguage that consists of universal semantic primitives (Wierzbicka 1990, 1992a, 1992b, 1999). In accordance with this aspiration to universality, natural semantic metalanguage is used especially for contrastive descriptions of emotions that aim at differentiating them either intralinguistically or comparing them in different languages and cultures. In this approach, in order to arrive at the description of an emotion, a pragmatic analysis of prototypical situations in a given culture is carried out, the researcher's intuition being crucial.

In contrast to Wierzbicka's methodology, the lexical approach developed mainly by Zoltán Kövecses (1986, 1990, 1998, 2000, etc.) starts with the idea that ". . . language, particularly its lexicon, is a reflection of our conceptual system" (Kövecses 1990: 41). For this reason, it bases the description of the complex structure of emotion concepts on an analysis of conventionalized linguistic expressions, such as metaphors, metonymies, idioms, clichés, proverbs and collocations (Kövecses 1990: 43). The data used for studies in the lexical approach is either elicited (enquiries among students) or collected from lexicographical sources like Roget's University Thesaurus (Kövecses 1986: 50). The conceptual structure of the emotion is described on four levels: a system of conceptual metonymies associated with the emotion concept, a system of conceptual metaphors associated with the emotion concept, a set of concepts related to the emotion concept, and a prototypical cognitive model.

In the field of cognitive linguistics, as well as in linguistics in general, there is a growing trend towards using a corpus-based methodology. This is especially true with regard to metaphor research (cf., for example, Deignan 1999, 2005; Charteris-Black 2004; Gevaert 2001, 2005; Stefanowitsch 2005; 
Stefanowitsch and Gries 2006) and also to the study of emotions (Stefanowitsch 2006, Bednarek 2008a). Within the framework of conceptual metaphor theory, Stefanowitsch (2006) advocates very strongly for such an approach. The method he proposes (metaphorical pattern analysis) consists of choosing a lexical item from the target domain, extracting a random sample of its occurrences in the corpus, identifying all metaphorical expressions that the search word is a part of, and grouping them according to general mappings. Stefanowitsch's results show that most of the metaphors described in introspective studies (using Kövecses [1998] as reference point) can be identified through a corpus-based analysis and that additional metaphors can be found. Furthermore, an important advantage of a corpus-based approach is the possibility of quantifying results. In Stefanowitsch's study, quantification is used in order to find out which metaphors are most strongly associated with an emotion.

\subsection{Some methodological considerations}

a) Dealing with large quantities of data. Corpus-based analysis of metaphor is not methodologically simple. First there is the question of how to deal with the sheer amount of data obtained. If using a bottom-up approach on a very large electronic corpus, this means that either a vast number of concordances have to be analysed or some way of pre-selection has to be established. The procedure proposed by Charteris-Black (2004) consists of two steps: a qualitative study of the metaphors, which comprises identification, interpretation and explanation, followed by a quantitative concordance analysis. Stefanowitsch (2006) follows a similar approach (a qualitative analysis of part of the corpus and subsequent quantification). However, this author also complements his method with a top-down approach by carrying out specific searches for previously described metaphor types that have not been found in the original sample of 1000 hits (Stefanowitsch 2006: 79). This is plausible within the context of Stefanowitsch's aim of demonstrating that all the metaphor types identified through introspection can also be found through a corpus-based study. However it poses a methodological problem regarding sample size if the aim is simply to provide a corpus-based description of the metaphorical expression of the emotion word. Supposing that there are no reliable detailed previous studies, how big should the sample be so as to ensure that no relevant metaphor types are left out?

What the contributions of the authors cited above show is that we need to achieve a balance between the necessity of applying coherent methodological criteria and the limitations imposed on the research by corpus size. While it is not possible, when working with very large corpora, to analyse every single co-occurrence, the method should be defined coherently in a way that makes it 
possible to trace the metaphorical expressions as exhaustively as possible. I will deal with this issue in some detail in Section 3.

b) Retrieving and analysing the data. A corpus-based approach has certain limitations but it also offers additional possibilities. As Deignan puts it: "There is no way of, say, entering speaker meaning or a conceptual metaphor into a computer and being provided with a list of lexical items realising that particular meaning or metaphor" (1999: 197). While in the lexical approach the analysis starts with a conceptual domain (for example "pride") and the data analysed consists of conventionalized expressions, in a corpus-based approach, the starting point is necessarily different: As in Stefanowitsch's (2006) approach, in this study I start from a lexical unit ('fear'). This procedure yields data in the form of co-occurrences (for example heart, swallow, palpable). When looking at the resulting combinations of the search word and its co-occurrences, many of these might be the same as the conventionalized expressions analysed in the lexical approach (e.g., strike fear into someone's heart, swallow one's pride). However, the overall picture is bound to be slightly different for two main reasons:

- The list of co-occurrences only includes lexical units that occur in the vicinity of the search word ('fear' in this case). Expressions that are used figuratively to describe the emotion without naming it cannot be detected with this method. For example, we would not find expressions like make one's blood curdle as an expression of fear, unless the lexical unit 'fear' occurred within the span that has been defined for the search. It would of course be possible to design a second phase of the analysis, elaborating on every individual metaphor and metonymy. I have not done this here and feel it would not be feasible with such a complex object of study as the linguistic expression of emotions. However, taking into account the finding of Fussell and Moss (1998) that speakers tend to use figurative expressions in addition to the literal ones and not instead of them, this limitation of the data does not seem to be a substantial drawback of the method.

- A much wider range of contexts can be analysed because these are not limited to conventionalized expressions.

\subsection{Potential results}

The data that can be obtained through corpus analysis is thus more limited than that of the lexical approach in one respect and more wide-ranging in another. By means of analysing the data provided by the corpus analysis, we arrive at conclusions about the structure of the emotion concept. This structure is again similar to that of the lexical approach (it tells us something about conceptual metaphors and metonymies), but it also opens up some different possibilities. 
We are therefore going to look in more detail into the additional results that can be expected.

2.3.1. Conceptual proximity. Emotion words seem to have a strong tendency to co-occur with other lexical units expressing feelings, either similar or contradicting ones (for example 'love' — 'tenderness' vs. 'love' — 'hate'). Corpus analysis allows us to quantify the strength of the collocational bonds between the search word and the co-occurring items. However, is it also possible to use these data on co-occurrences to make inferences about how the complex category of an emotion concept is structured? We would probably be expecting too much if we tried to provide a description of the whole category and its internal relationships between central and peripheral members. Nevertheless, analysing the co-occurring emotion words can give us an idea about which elements belong to the emotion category, which are most strongly connected to the emotion word that was used as starting point, as well as about other emotions that are frequently associated with it.

2.3.2. Evaluation and description. Apart from allowing us to have a closer look at well-known aspects of the structure of emotion concepts like metaphor and metonymy, the main advantage of a corpus-based approach is the possibility of making use not only of the material devices (the corpora themselves, the lists of co-occurrences, and the statistical measures) but also of conceptual tools developed in corpus linguistics.

The concepts I am proposing to employ are two key notions of corpus studies: semantic preference and semantic prosody, which go back to John Sinclair's work on collocations. Together with collocational profile (i.e., lexical realisation) and colligational patterns (lexicogrammatical realisations), semantic preference and semantic prosody bind words tightly into their contexts and into linguistic convention, forming extended units of meaning (Sinclair 1996).

Of these four points, semantic preference and prosody are probably the most difficult to describe, as they focus on connotational and evaluative aspects. In recent years, these concepts have been examined critically (e.g., Whitsitt 2005), renamed (cf. Hoey's (2005) semantic association and Stubb's (2001) discourse prosody), re-explained (Morley and Partington 2009), re-examined (Hunston 2007, Bednarek 2008b) and also increasingly used in cross-linguistic contexts (Tognini-Bonelli 2001, Xiao and McEnery 2006, Stewart 2009, Munday in press). Like Bednarek (2008b), I consider that it is useful to maintain distinction between the two concepts and, as they have not always been defined homogeneously, I will clarify their use here:

a) Semantic preference refers to the semantic subsets a word's collocates predominantly belong to. In this study, it is used to determine the way the emo- 
tion is described and how it combines with (groups of) other lexical units. For this purpose, the semantic fields of the collocates of 'fear' are analysed and classified, which leads to identifying the main descriptive dimensions of the concept and of typical co-occurrence partners from a functional point of view (causes of fear, experiencers of fear, etc.).

b) Semantic prosody, on the other hand, is a connotation that can be transferred to a word if it co-occurs frequently with words carrying a positive or negative evaluative load. Classic examples of semantic prosody include:

- 'happen', for which Sinclair (1987) showed that things that happen are usually negative;

- 'utterly', which Louw (1993) showed to be overwhelmingly combined with adjectives expressing something negative; and

- 'cause', which according to Stubbs (1995) collocates most frequently with negative nouns like harm, alarm, quarrel, danger, etc.

Semantic prosody thus reveals an evaluative potential of the extended unit of meaning that is not always obvious (cf. Channell 2000) and which takes the analysis to a pragmatic level (Sinclair 1996: 87).

Several aspects of semantic prosody have been controversial in recent years. One of them is over the possibility of an evaluative connotation (the good or bad semantic prosody) being transferred from one lexical unit to another (cf. Withsitt 2005). Hunston (2007: 266) points out that the idea of the carrying over of attitudinal meaning from one context to another provides a good explanation for implied meaning, but that this does not mean that it necessarily always happens. The issue is clearly beyond the scope of this article; however, in the case of emotion concepts, which inherently already bear an important evaluative load, it is probably not the most important question. What does matter in the context of analysing emotion concepts is the idea that the typical surroundings of a lexical unit may reveal attitudinal meaning and evaluative connotations that relate to the concept.

Another open question is whether an analysis of semantic prosodies should concentrate essentially on positive or negative evaluation (Morley and Partington 2009) or if it is also useful to identify more differentiated aspects of attitudinal meaning (Hunston 2007, Bednarek 2008b). Possibly the two options are more compatible than it seems, e.g., through the "Linnaean-style binomial notation" proposed by Morley and Partington (2009: 141), such as [good: pleasurable], [good: being in control], [bad: difficult], and [bad: not being in control].

For the purpose of this study, those co-occurrences of the emotion word that present an additional evaluative load will be recorded separately with the aim of assessing a potential positive or negative connotation of some kind. 


\section{Applying the method: A corpus-based analysis of "fear"}

\subsection{Corpus choice}

For the purpose of this study, there are no special needs regarding genre, mode or time of the texts included in the corpus. Size, however, is important as emotion words are not high frequency words and a very large amount of text material is needed in order to draw conclusions about their behaviour in context. The best choice, therefore, will be using a very large, general purpose corpus of several hundreds of millions of words rather than compiling a corpus tailormade to the needs of the analysis and necessarily smaller. For English, there are several large and freely available corpora, from which I have chosen the Corpus of Contemporary American English (Davies 2008), containing approximately 300 million words at the time of the search. This corpus is continually updated, which means that results may change slightly when a search is carried out at different moments in time.

\subsection{Search process}

Out of the range of possibilities offered by corpus-analysis software (including word lists, statistics of word frequencies, concordances and key words in context), the most useful tool for semantic analysis seems to be that of extracting a list of co-occurrences for a given search word. This is the (semi)automatic part of the analysis, although this does not mean there are no decisions to be taken in this phase of the process. There are large differences in the search facilities offered and the type of data provided. Even if this does not influence the results of the study directly, the availability or absence of certain facilities is bound to make the search process either easier or more cumbersome. The following are a few of the features afforded by most corpora and which I have found useful in order to rationalize the search process:

Regarding the search word (node):

- Searching by lemmas, which makes it possible to find different forms of the lexical unit in one search. This might not be relevant in our case because the result of the search for 'fear' will automatically include the occurrences of the plural noun 'fears'. However, it does matter in languages in which the plural or other inflectional forms differ more substantially from the singular form (e.g., the German 'Angst'/‘̈̈ngste') or when the search word is a verb. ${ }^{2}$

2. It has been shown that different forms of the same lemma can behave differently. Although this is also true for 'fear'/ 'fears', these differences have not been analysed in depth since the focus of this research is on the overall behaviour of the concept, taking together its occurrences in singular and in plural form. 
- Limiting the search by the part of speech (POS) of the search word. Collocations may differ considerably between the noun 'fear' and the verb 'fear'. This is especially important in contrastive studies as in most languages verb and noun do not coincide in their form.

Regarding texts:

- Choosing particular sub-corpora according to genre or time. For the purpose of this study, the only restriction in this sense was the limitation to written sources. In contrastive studies this can be also used to make the corpora more comparable by, for example, excluding genres that are not present in another corpus.

Regarding co-occurrences:

- Differentiating the search with respect to the POS of the co-occurring word. This is useful in order to facilitate the subsequent phase of classifying the co-occurrences. For example, conceptual metaphors and metonymies are often expressed through verbs and nouns, while an adjective search will reveal many things about how the emotion is described. It also makes it possible to adjust the search span according to POS. For example, the classic 4-word span is adequate when looking for nouns and verbs. However, searching for adjectives and prepositions with the same span produces a lot of noise and I chose to reduce it to 2 for these.

- Searching not only for co-occurrences but also for compounds containing the search word (i.e., *fear, fear*). This is especially interesting in view of contrastive studies that combine languages whose tendencies towards compounding are not equally strong. I have found it useful, however, to exclude lexicalised compounds (e.g., fearful) as their extremely high frequency may distort the results considerably.

Regarding results:

- Grouping results by lemmas. This means that different forms of a word are counted together and shown in their uninflected form. Examples include: paralyze, paralyzed $\rightarrow$ paralyze; terror, terrors $\rightarrow$ terror.

- Using different possibilities for sorting the results. For example, it can be useful to carry out a search twice, sorting it once by absolute frequency and once by one of the statistical measures offered by the corpus that are intended to establish the relevance of a collocation. ${ }^{3}$ In this way, one finds both the most frequent collocates and those that appear especially often together with the node.

- Establishing a minimum frequency of co-occurrence in order to exclude extremely rare combinations. This is even more important when using a

3. Commonly used measurements of this type are the MI-index (mutual information), loglikelihood or t-score. 
measure like the MI-index ${ }^{4}$. If no minimum frequency is set, very strange words (or even typos) score very highly on this index despite the fact that they only occur once or twice in the whole corpus - because they always do in combination with the search word!

- Establishing a maximum number of hits. This can be used as a means to keep the amount of data that has to be analysed on a manageable level without having to limit the analysis to random samples.

Table 1 shows the searches that were carried out applying these criteria: ${ }^{5}$

Table 1. Searches carried out in the COCA corpus

\begin{tabular}{lllllll}
\hline & $\begin{array}{l}\text { Search } \\
\text { string }\end{array}$ & $\begin{array}{l}\text { POS of } \\
\text { co-occurrence }\end{array}$ & Sorted by & $\begin{array}{l}\text { Minimum } \\
\text { frequency }\end{array}$ & $\begin{array}{l}\text { left/right } \\
\text { span }\end{array}$ & $\begin{array}{l}\text { Maximum no. } \\
\text { of hits }\end{array}$ \\
\hline 1 & fear.[nn*] & noun & frequency & 2 & $4 / 4$ & 400 \\
2 & fear.[nn*] & noun & $\begin{array}{l}\text { relevance } \\
\text { (MI-index) }\end{array}$ & 5 & $4 / 4$ & 400 \\
3 & fear.[nn*] & verb & frequency & 2 & $4 / 4$ & 400 \\
4 & fear.[nn*] & verb & relevance & 5 & $4 / 4$ & 400 \\
5 & fear.[nn*] & adjective & frequency & 2 & $2 / 2$ & 400 \\
6 & fear.[nn*] & adjective & relevance & 5 & $2 / 2$ & not necessary ${ }^{6}$ \\
7 & fear.[nn*] & adverb & frequency & 2 & $2 / 2$ & not necessary \\
8 & fear.[nn*] & preposition & frequency & 2 & $0 / 2^{7}$ & not necessary \\
9 & fear.[nn*] & preposition & frequency & 2 & $2 / 0$ & not necessary \\
10 & fear* & - & frequency & 2 & - & not necessary \\
11 & $*$ fear & - & frequency & 2 & - & not necessary \\
\hline
\end{tabular}

\subsection{Classification process}

Following the search process described above, the corpus provides us with a list of co-occurrences (or, rather, several lists if complex searches are carried out). In the second, qualitative phase, these lists are then analysed and classified. Classifying the co-occurrences means deciding whether they are relevant for one (or more) of the following points:

a) The metaphorical understanding of the emotion (e.g., overwhelmed by fear $\rightarrow$ FEAR IS AN ATTACKER)

4. The mutual information index compares the observed frequency of co-occurrence of two items to what could be statistically expected if they only co-occurred by chance.

5. Additionally, for all searches the sections of the corpus were limited to fiction, magazine, newspaper and academic and the results were always grouped by lemmas.

6. In these cases there was no need to determine a maximum number of hits because there were less than 400 co-occurrences with a minimum frequency of two.

7. It proved useful to search separately for prepositions occurring before and after the noun (e.g., fear in one's heart vs. to be in fear). 
b) Evidence for metonymic usages (e.g., choke $\rightarrow$ Disturbed breathing as a sign for fear)

c) Relationships to other emotion concepts (e.g., loathing)

d) A description of the emotion (e.g., ever-present)

e) An evaluation of the emotion (e.g., hidden)

Of course, not every co-occurrence is relevant for the analysis. Even highly frequent items may not reveal anything about any of the five categories. In the case of fear, some of these "unrevealing" co-occurrences were, for example, factor, way, or day. In a second step, this kind of qualitative filtering is also used to check the quantitative results. This means that when a collocate is classified into one of the categories, a closer examination of the contexts is carried out in order to count only those instances that are actually relevant. For example, in the COCA corpus 'bad' and 'fear' co-occur 59 times, but only 5 of the contexts can be considered relevant in the sense that 'bad' is used as an intensifier of 'fear', like in the following examples.

\begin{tabular}{llll}
\hline Year & Corpus section & Title & Concordance line \\
\hline 1994 & NEWS & WashingtonPost & $\begin{array}{l}\text { I just felt totally trapped. I did not know what } \\
\text { to do and the fear got so bad I was unable to } \\
\text { function like in my normal life.” } \\
\text { get hurt. A safe way, I figured, of overcoming } \\
\text { a real bad fear. Besides, you probably also } \\
\text { recall how I reacted when the Old Guy told }\end{array}$ \\
\hline
\end{tabular}

On the other hand, the following contexts are left out in the count of relevant examples.

\begin{tabular}{llll}
\hline Year & Corpus section & Title & Concordance line \\
\hline 2008 & MAG & GolfMag & $\begin{array}{l}\text {, powerful swing. MANY OF US get caught up in } \\
\text { swing thoughts and our fear of hitting bad shots, a } \\
\text { combination that results in, what else-bad shots } \\
\text { decide not to hold as many lobbyist-sponsored } \\
\text { fundraising events, especially in Washington, for fear } \\
\text { of bad publicity (and possible indictment against } \\
\text { themselves) and raise much more of }\end{array}$ \\
\hline
\end{tabular}

3.3.1. The identification of metaphorical expressions. The metaphorical conceptualisation of the emotion concept is the main focus of this analysis and has also been the object of extensive previous research. I will therefore explain the identification and classification process of the metaphorical expressions in more detail. 
The identification process follows the core of the procedure proposed by the Pragglejaz Group (2007). As we are not dealing with linear textual analysis, though, but starting with a list of co-occurrences, the order of steps has to be different:

a) The list of co-occurrences is scanned for possible candidates that might be part of a metaphorical expression.

b) Contexts of these are retrieved (concordance lines).

c) It is established whether there is a contrast between contextual meaning and the more basic meaning of the lexical unit (i.e., a more concrete or precise meaning, one that is related to bodily action or that is historically older, cf. Pragglejaz Group 2007: 3). ${ }^{8}$

d) Only those instances in which a contrast exists are counted.

The qualitative context-based filtering mentioned above is especially relevant with respect to metaphor identification. Not only is it used to establish whether an expression is used metaphorically but also whether it is used in more than one sense. For example, it can happen that one part of the instances of a cooccurring lexical item is classified in one category, while another part is in another. So, some instances of the co-occurrence override were classified as an expression of the metaphor FEAR IS SOMETHING THAT DOMINATES.

\begin{tabular}{llll}
\hline Year & Corpus section & Title & Concordance line \\
\hline 2002 & ACAD & ForeignAffairs & $\begin{array}{l}\text { to signal that the United States was not prepared } \\
\text { to defend local governments, the fear of Soviet } \\
\text { control overrode these concerns. In 1957, in } \\
\text { response to increased instability }\end{array}$ \\
\hline
\end{tabular}

Others, like the following, belong to the category FEAR IS SOMETHING THE SELF FIGHTS BACK AGAINST.

\begin{tabular}{llll}
\hline Year & Corpus section & Title & Concordance line \\
\hline 1990 & FIC & BkSF:Iris & $\begin{array}{l}\text { It was all fascinating, but not quite fascinating enough } \\
\text { to override the growing fear in her. Despite the fact } \\
\text { that it was yet to come on formally, } \\
\text { having told him I'd been a teacher? \# And if I had } \\
\text { overridden fear and dared ask him, Donny, please } \\
\text { close the curtain, wouldn't I }\end{array}$ \\
\hline
\end{tabular}

8. In case of doubt, the Merriam-Webster Online dictionary was used for establishing this contrast. When there were more than 50 contexts for a co-occurrence, the total number of metaphorical contexts was estimated on the basis of the proportion found in the first 50 instances. 
As a certain degree of subjectivity in the classification of metaphorical expressions is inevitable, this process was done in several steps. First, all the expressions were classified independently by two researchers. The discussion of divergences in the classifications led to the establishment of specific criteria for problematic cases, which were then applied coherently to the whole data set. The final result was then checked again by both researchers. The criteria are the following:

- In the case that an expression could be interpreted according to more than one metaphor (e.g., gripped by fear as an instance of FEAR IS AN ATTACKER or FEAR IS A HUMAN BEING), the analysis is first done on the highest level of the typology. Gripped by fear, for instance, seems more indicative of the conceptualisation of "fear" as an ANTAGONIST than as an AUTONOMOUS FORCE. It is therefore classified in the category FEAR IS AN ATTACKER.

- If an expression is already metaphorical in the source domain, only the last link in this metaphorical chain is taken into account. For example, the cooccurrence of 'fear' with severe or stricken with is classified as an instance of FEAR IS AN ILLNESS, irrespective of the fact that in combination with an illness these could in turn be interpreted as metaphorical (THE ILLNESS IS A HUMAN BEING / A WEAPON).

3.3.2. The classification of metaphorical expressions. The starting point for the classification of the metaphor expressions identified in this way is a typology that was itself the result of a corpus-based contrastive analysis of several emotion concepts, including "fear", "envy" and "pride" (Oster 2010). This study confirmed that most metaphors found in the corpus data could be accounted for by one of the metaphor types described in the lexical approach, but it also introduces some additional subtypes.

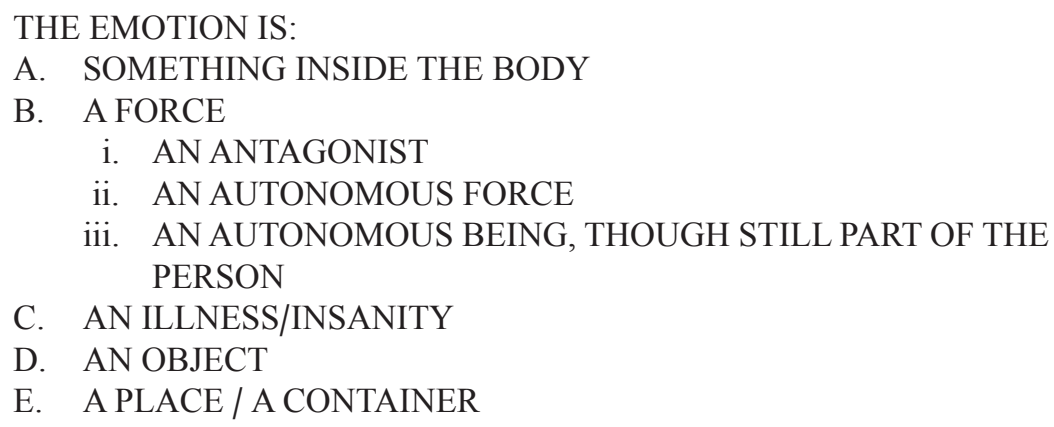


This typology is of course heavily influenced by Kövecses' studies, but it groups the types of metaphor differently. Furthermore, the conceptual metaphors at the highest level of abstraction are formulated in a slightly more general way, in order to account for minor differences in metaphorical expressions between languages without postulating conceptual metaphors that differ at the highest level.

For example, type A (THE EMOTION IS SOMETHING INSIDE THE BODY) is similar to Kövecses' conceptual metaphor THE EMOTION IS A FLUID IN A PRESSURIZED CONTAINER. The more general formulation used here owes to the fact that in Spanish and German few examples were found that evidence the conceptualization of the emotion as a fluid and even fewer that would make one think of a pressurized container.

In the case of conceptual metaphor B (THE EMOTION IS A FORCE), ${ }^{9}$ what the three subtypes have in common is that the emotion is characterised by being a distinct entity that is autonomous, up to the point of a conceptualization as a person or an animal. I distinguish three subtypes that highlight different features.

(i) AN ANTAGONIST: The emotion is an (external) force that attacks the self and is fought against.

(ii) AN AUTONOMOUS FORCE: The emotion is a force that acts independently and is not controlled by the self.

(iii) AN AUTONOMOUS BEING, THOUGH STILL PART OF THE PERSON: Here, there is a stronger link to the self. The emotion is conceived as "a person inside the person", which can be passive (she hurt my pride), or active if it acts instead of the self (Spanish: mi orgullo se subleva).

Depending on the kind of emotion we are looking at, some types are more relevant than others. For example, in the case of negative emotion concepts like "fear" or "envy", there is a predominance of metaphorical expressions that represent the emotion as coming from the outside and attacking the person. Emotions like "pride", on the other hand, which can be seen as positive, are more frequently seen as an entity which belongs to the person even if it is autonomous.

9. We could also understand types A, B and C according to a generic-level "master metaphor" EMOTION IS FORCE, as suggested by Kövecses (2000: 61-80), and consider them specificlevel instantiations of this metaphor. However, EMOTION IS FORCE is used here in a more restricted sense, applying it only to the three subtypes of B (OPPONENT, AUTONOMOUS FORCE AND AUTONOMOUS BEING INSIDE THE PERSON), thus stressing the differentiating traits of the three major metaphors $(\mathrm{A} \rightarrow$ SOMETHING INSIDE, $\mathrm{B} \rightarrow$ FORCE, $\mathrm{C} \rightarrow$ ILLNESS/MADNESS). On the other hand, it does not seem possible to include types $\mathrm{D}$ (THE EMOTION IS AN OBJECT) and E (THE EMOTION IS A PLACE/CONTAINER) in the EMOTION IS FORCE generic-level metaphor. 
3.3.3. Finding evidence for conceptual metonymy. In the lexical approach to the study of emotions, we speak of conceptual metonymy when an emotion is represented by its physiological effects or by the behavioural reactions it generates. This makes the limitation of the corpus-based method as explained above especially relevant: Owing to the methodological necessity of including the node 'fear' in the corpus search, it is only possible to find instances of physiological effects or behavioural reactions if the emotion itself is also mentioned, whereas there does not seem to be a straightforward way of tracing instances in which the physical effect actually stands for the emotion. Nevertheless, the co-occurrences include many expressions that evidence various physical or behavioural effects of the emotion. An analysis of these cooccurrences can probably provide us with interesting insights into the question of which effects are prevalent in the conceptualization of an emotion in a given language/culture.

\subsection{Ways of quantifying the relevance of results}

Many corpus-based semantic studies make use of corpus data in order to obtain only qualitative information on their subject. For example, in his account of corpus studies in lexical semantics and the role of co-occurrence analysis, Stubbs (2002: 73) chooses not to present any figures on the statistical significance of the data. The two main reasons presented for this decision are that variables in natural language texts are not randomly distributed and that the levels of co-occurrence are far above what one might expect by chance.

However, even if the linguistic data in text corpora is not randomly distributed, this does not mean that statistic analysis cannot be performed or that its results are not meaningful. In fact, the possibility of quantifying results is one of the main advantages of the corpus-based approach. Only this will enable us to assess the productiveness of certain metaphors and to make comparisons either intralinguistically, for example, for questions like "Are there metaphors that are more frequent for some emotions than for others?" (cf. Stefanowitsch 2006) or "Do we use the same type of metaphors now as we did two hundred years ago?" or interlinguistically ("Is a certain type of metaphor more frequent in one language than in another?").

One common way of quantifying the relevance of collocations is the mutual information index. However, this index tends to give high scores to very rare words. In view of these difficulties, I have adopted an approach that is based on Kövecses' reflection that "... the more frequent and numerous the linguistic metaphorical expressions linking the two domains, the more stable the connections between them in the brain may be" (2005: 34). Kövecses' hypothesis actually seems to link the two observable parameters (frequency and quantity of metaphorical expressions) to the cognitive entrenchment of the metaphors 
in the human brain. This is a plausible hypothesis, but I do not want to take the conclusions from a corpus-based study this far. Nevertheless, I think that these parameters are useful in order to quantify the relevance of certain metaphorical usages in a given corpus and in the section of language it was designed to represent (in the case of our study: contemporary written American English). The following parameters were thus adopted as a measurement of relevance of the results:

- The number of different linguistic expressions co-occurring with 'fear' in the corpus that are a realisation of a certain metaphor or metaphor subtype. For example, there are eight different linguistic expressions for the metaphor FEAR IS A BURDEN (outweigh, carry, alleviate, weight, fraught with, heavy, fear-charged, fear-laden).

- The absolute frequency of linguistic expressions, i.e., how many times an item co-occurs with 'fear'. For example, the absolute frequency of outweigh as co-occurrence partner of 'fear' in our corpus is 13, and for the metaphor FEAR IS BURDEN it is 59 (the sum of outweigh [13], carry [12], alleviate [12], weight [10], fraught with [4], heavy [4], fear-charged [2] and fear-laden [2]). ${ }^{10}$

- The relative frequency, i.e., the absolute frequency divided by the total number of classified metaphorical co-occurrences. For example, the relative frequency of outweigh as co-occurrence partner of 'fear' is $0.2 \%$ out of a total of 5516 metaphorical co-occurrences.

\section{Results}

\subsection{Conceptual metaphors}

4.1.1. Metaphor types and subtypes. When looking at the results from a qualitative point of view, we find that all the major types of conceptual metaphor but one are used to express the concept of "fear". "Fear" is described as a FORCE that is either hostile towards the self(Bi) or out of its control (Bii), but

10. As parallel to the corpus-linguistic concepts "type" and "token", some researchers (Gevaert 2001, 2005; Koller 2006, 2008) have called "type" what is called "number of different expressions" here and "token" what I call "absolute frequency". In order to avoid confusion between the well-established notion of "type-token ratio" as a measure of the lexical variety of a text and the "creativity ratio" I am going to introduce, I prefer to maintain the more transparent terminology explained above. 
there is no evidence for metaphors that stress that the emotion is part of the person (Biii). Furthermore, the metaphorical expressions found for metaphor types A, B, C, D and E show distinct features, which allows a further classification into subtypes. I will now briefly explain the most important aspects of every metaphor and refer the reader to Appendix 1 for a complete list of linguistic expressions (with quantities in square brackets) for every metaphor and metaphor subtype.

\section{A. FEAR IS SOMETHING INSIDE THE BODY}

On a general level, one of the most pervasive signs for the conceptualization of fear as something located inside the human body are prepositional or adverbial structures like fear in ... (persons, body parts), strike fear into . . ., fear moves through ..., fear inside, or fear within. Furthermore we find a great variety of co-occurrences that evidence that fear is located in or affects specific body parts (heart, stomach, blood, etc.) or the soul.

Additionally, there are many metaphorical expressions that allow us to subdivide the basic conceptual metaphor into subtypes. For example, many of the metaphorical expressions - but by no means all of them - are related to the conceptualization of the emotion as a liquid and/or to more general metaphors like MORE IS UP: Fear is a liquid inside the body (wave of fear, trickle of fear, fear drains from $s / o$, etc.) and when it becomes stronger it tends to go up in the body like a liquid in a container (rise (in/inside) s/o, swallow, force down one's fear, etc.). Other aspects are that the emotion comes from the outside ( fill, inspire, instil( l), etc.), that an emotion that is strong is deep inside the body (deep, deep-seated, ingrained, profound, etc.) and that it emanates from the body and is thus perceptible (smell, fear-scent).

\section{Bi. FEAR IS AN ANTAGONIST}

Fear is also very frequently understood as an external force that acts against the experiencer. This can take the form of an attack (grip, seize, overwhelming, etc.), domination (haunt, take hold of, dominate, etc.) or destruction (gnawing, all-consuming, nagging, etc.). It may cause pain (twinge, numb one's fear, tortured by fear) or be a burden (be outweighed by, carry, alleviate, etc.). The attacker can also be conceptualized as an evil force (haunt, possessed by). On the other hand, there is the possibility of counterattack (conquer one's fear, overcome, fight (back), etc.).

\section{Bii. FEAR IS AN AUTONOMOUS FORCE}

Expressions relating to the general idea of fear being an autonomous force acting independently and not controlled by the person are spread, uncontrollable and powerful. More specifically, the emotion can be seen as a human being or animal (arouse, awaken, creep, etc.) or as a plant (sow, deep-rooted). It is also 
described as a liquid ${ }^{11}$ (wave offear, sweep, wash over s/o, etc.) or fire (spark, fuel, stoke, etc.).

\section{FEAR IS AN ILLNESS/INSANITY}

Another widespread conceptualization of "fear" is that of an illness (suffer, develop a fear, sick with, etc.) or madness (crazy with fear, mad with, insane with/from). ${ }^{12}$

\section{FEAR IS AN OBJECT}

Fear can be perceived as a physical object in general (palpable, push away, struck with fear), as a piercing object (edge, sharp), a possession (lose, bring, take, etc.), as food (feed on fear, to be fed fear) or an obstacle (break through fear, get over/past fear).

\section{E. FEAR IS A PLACE/CONTAINER}

The conceptualization of fear as a place or container is mainly expressed through the use of prepositions (in one's fear, out of fear, through one's fear, over one's fear). Some expressions also convey the idea of fear as something that surrounds people (amid fear, thick in the air).

4.1.2. Frequency of occurrence. A quick glance at the most and least frequent co-occurrences (cf. Table 2) shows two things: the importance of the conceptualisation of "fear" as SOMETHING INSIDE THE BODY (in, into, heart, fill, inspire), and the fact that prepositions enjoy a special status. Four out of the ten most frequent co-occurring items are prepositional constructions and these are extremely frequent in comparison to other metaphorical expressions.

In spite of the fact that there are rather few different prepositions expressing a metaphorical understanding of an emotion (in, into, out of, past, through, over), this important numerical difference between prepositional constructions and other word classes leads to a considerable impact of the former on the overall distribution of the different metaphors. If prepositions are taken into account (cf. the first column of each parameter in Table 3), the most prevalent metaphor is FEAR IS SOMETHING INSIDE THE BODY (2072 instances, i.e., $37.6 \%$ out of a total of 5516), followed by FEAR IS A PLACE/ CONTAINER (26.5\%) and, with less incidence, FEAR IS AN ANTAGONIST (14.5\%), FEAR IS AN OBJECT (11.8\%) and FEAR IS AN AUTONOMOUS FORCE (7.3\%). In comparison, FEAR IS AN ILLNESS/INSANITY (2.3\%) can almost be considered marginal.

11. In contrast to one of the subtypes of A (A LIQUID INSIDE THE BODY), the liquid here is outside the person, surrounding it.

12. In both cases, contexts dealing with fear as an actual mental illness, i.e., not in a metaphorical sense, were not taken into account. 
Table 2. The ten most and least frequent co-occurrences

\begin{tabular}{lc}
\hline Co-occurrences & Absolute subtype frequency \\
\hline in one's fear & 1000 \\
fear in ... (persons, body parts) & 800 \\
out of fear & 400 \\
have & 287 \\
overcome & 203 \\
heart & 170 \\
lose & 150 \\
fill & 114 \\
(strike, etc.) fear into .... & 100 \\
inspire & 95 \\
$\ldots$ & \\
$\ldots$ & 2 \\
lungs & 2 \\
leak fear & 2 \\
stricken with & 2 \\
constrained by fear & 2 \\
take over & 2 \\
driven & 2 \\
beget fear & 2 \\
fear-engendering & 2 \\
ignite & 2 \\
thick & 2 \\
\hline
\end{tabular}

Table 3. Overall distribution of conceptual metaphors (with and without taking prepositional constructions into account)

\begin{tabular}{|c|c|c|c|c|c|c|}
\hline \multirow[t]{2}{*}{$\begin{array}{l}\text { Conceptual metaphor: } \\
\text { FEAR IS }\end{array}$} & \multicolumn{2}{|c|}{$\begin{array}{l}\text { Absolute } \\
\text { frequency }\end{array}$} & \multicolumn{2}{|c|}{ Relative frequency } & \multicolumn{2}{|c|}{$\begin{array}{l}\text { Number of } \\
\text { different } \\
\text { expressions }\end{array}$} \\
\hline & $\begin{array}{l}\text { With } \\
\text { prep. }\end{array}$ & $\begin{array}{l}\text { Without } \\
\text { prep. }\end{array}$ & $\begin{array}{l}\text { With } \\
\text { prep. }\end{array}$ & $\begin{array}{l}\text { Without } \\
\text { prep. }\end{array}$ & $\begin{array}{l}\text { With } \\
\text { prep. }\end{array}$ & $\begin{array}{l}\text { Without } \\
\text { prep. }\end{array}$ \\
\hline $\begin{array}{l}\text { A. SOMETHING INSIDE } \\
\text { THE BODY }\end{array}$ & 2072 & 1087 & $37.6 \%$ & $35.0 \%$ & 51 & 46 \\
\hline B i. AN ANTAGONIST & 801 & 796 & $14.5 \%$ & $25.7 \%$ & 52 & 51 \\
\hline $\begin{array}{l}\text { B ii. AN AUTONOMOUS } \\
\text { FORCE }\end{array}$ & 401 & 401 & $7.3 \%$ & $12.9 \%$ & 36 & 36 \\
\hline C. AN ILLNESS/INSANITY & 127 & 127 & $2.3 \%$ & $4.1 \%$ & 18 & 18 \\
\hline D. AN OBJECT & 651 & 651 & $11.8 \%$ & $21.0 \%$ & 15 & 15 \\
\hline E. A PLACE/CONTAINER & 1459 & 36 & $26.5 \%$ & $1.2 \%$ & 9 & 4 \\
\hline Total & 5516 & 3103 & $100 \%$ & $100 \%$ & 181 & 170 \\
\hline
\end{tabular}


However, if we only count those word classes traditionally thought of as having stronger lexical weight (nouns, verbs, adjectives), which results in a total of 3103 instances, the picture is somewhat different, with a more even distribution among the three major metaphor types A (35\%), B (38.6\% taking together the two subtypes) and D (21.0\%). The largest difference is to be found in the PLACE/CONTAINER metaphor. While it is the second most important metaphor when taking into account prepositions, there are very few expressions that include nouns, verbs or adjectives, which makes the frequency of this metaphor drop to $1.2 \%$ if we only count the latter. This might be interpreted as indicating that the conceptualisation of an emotion as a place or container is a very basic and conventionalized metaphor, but barely ever consciously employed.

Because of the large differences in frequency between prepositions and other word classes, it seems convenient to treat prepositional expressions separately when comparing the quantitative results for individual metaphors in more detail. Table 4 below (Section 4.1.3) therefore shows the frequency of every subtype without taking into account prepositional expressions in order to be able to appreciate the differences more clearly. From the point of view of frequency, the major subtypes are:

- FEAR IS A POSSESSION (525 instances - 16.9\% of a total of 3103)

- IT IS SOMETHING THE SELF FIGHTS BACK AGAINST (345$11.1 \%)$

- IT IS LOCATED IN OR AFFECTS SPECIFIC BODY PARTS (329$10.6 \%$ )

- IT COMES FROM THE OUTSIDE (414-9.9\%)

- $\quad$ IT IS A HUMAN BEING OR ANIMAL (217-7.0\%)

- IT IS UNSPECIFICALLY LOCATED INSIDE THE BODY (216-7.0\%)

- $\quad$ IT IS AN ATTACKER (162-5.2\%)

4.1.3. Productivity and creative use. Frequency of occurrence alone is not enough to describe the metaphorical expression of an emotion, though. There are some metaphors that are highly frequent but only very few different linguistic expressions can be found for them. Apart from the FEAR IS A PLACE/ CONTAINER metaphor, which is almost exclusively present in rather few prepositional structures, there are other metaphor subtypes whose materialisation is limited to almost stereotyped expressions, for example fill with and its synonyms for the metaphor FEAR IS SOMETHING THAT COMES FROM the OUTSIDE. In contrast, there are other metaphors that are not only frequent but also show a high degree of productivity and seem to be explored creatively in language use. This is the case of FEAR IS FIRE, for which we find nine different co-occurrences (spark, fuel, flash, stoke, flare, extinguish, burn, fire, ignite). 
Table 4. Distribution of metaphor subtypes

\begin{tabular}{|c|c|c|c|c|c|c|}
\hline & FEAR IS & ASF & $\%$ & NDE & PI & CR \\
\hline & $\begin{array}{l}\text { SOMETHING THAT IS } \\
\text { UNSPECIFICALLY LOCATED } \\
\text { INSIDE THE BODY }\end{array}$ & 216 & $7.0 \%$ & 4 & 16.8 & 0.3 \\
\hline & $\begin{array}{l}\text { SOMETHING THAT IS LOCATED } \\
\text { IN OR AFFECTS SPECIFIC BODY } \\
\text { PARTS }\end{array}$ & 329 & $10.6 \%$ & 15 & 95.8 & 0.8 \\
\hline & $\begin{array}{l}\text { SOMETHING THAT AFFECTS } \\
\text { THE SOUL }\end{array}$ & 29 & $0.9 \%$ & 1 & 0.6 & 0.6 \\
\hline & $\begin{array}{l}\text { SOMETHING THAT COMES } \\
\text { FROM THE OUTSIDE }\end{array}$ & 414 & $9.9 \%$ & 8 & 53.5 & 0.5 \\
\hline 仓ิ & $\begin{array}{l}\text { SOMETHING THAT IS DEEP } \\
\text { INSIDE THE BODY WHEN IT IS } \\
\text { STRONG }\end{array}$ & 75 & $2.4 \%$ & 7 & 10.2 & 1.7 \\
\hline 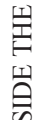 & $\begin{array}{l}\text { SOMETHING THAT TENDS TO } \\
\text { GO UP IN THE BODY WHEN IT } \\
\text { BECOMES STRONGER }\end{array}$ & 66 & $2.1 \%$ & 6 & 7.7 & 1.6 \\
\hline 光 & A LIQUID INSIDE THE BODY & 11 & $0.4 \%$ & 3 & 0.6 & 4.9 \\
\hline 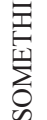 & $\begin{array}{l}\text { SOMETHING THAT EMANATES } \\
\text { FROM THE BODY AND IS THUS } \\
\text { PERCEPTIBLE }\end{array}$ & 47 & $1.5 \%$ & 2 & 1.8 & 0.8 \\
\hline$\dot{<}$ & TOTAL & 1087 & $35.0 \%$ & 46 & 970.7 & 0.8 \\
\hline & AN ATTACKER & 162 & $5.2 \%$ & 8 & 25.2 & 0.9 \\
\hline & SOMETHING THAT DOMINATES & 95 & $3.1 \%$ & 15 & 27.7 & 2.9 \\
\hline & A BURDEN & 59 & $1.9 \%$ & 8 & 9.2 & 2.5 \\
\hline & SOMETHING THAT DESTROYS & 38 & $1.2 \%$ & 4 & 3.0 & 1.9 \\
\hline & $\begin{array}{l}\text { SOMETHING THE SELF FIGHTS } \\
\text { BACK AGAINST }\end{array}$ & 345 & $11.1 \%$ & 7 & 46.9 & 0.4 \\
\hline$\overbrace{0}^{\infty}$ & $\begin{array}{l}\text { SOMETHING THAT CAUSES } \\
\text { PAIN }\end{array}$ & 33 & $1.1 \%$ & 4 & 2.6 & 2.2 \\
\hline 乬 & AN EVIL FORCE & 45 & $1.5 \%$ & 3 & 2.6 & 1.2 \\
\hline Z & DARKNESS & 19 & $0.6 \%$ & 2 & 0.7 & 1.9 \\
\hline $\bar{m}$ & TOTAL & 796 & $25.7 \%$ & 51 & 788.1 & 1.2 \\
\hline
\end{tabular}


Table 4 (Continued)

\begin{tabular}{|c|c|c|c|c|c|c|}
\hline & FEAR IS & ASF & $\%$ & NDE & PI & $\mathrm{CR}$ \\
\hline & $\begin{array}{l}\text { AN UNSPECIFIC AUTONOMOUS } \\
\text { FORCE }\end{array}$ & 75 & $2.4 \%$ & 5 & 7.3 & 1.2 \\
\hline & A PLANT & 17 & $0.5 \%$ & 2 & 0.7 & 2.1 \\
\hline & A HUMAN BEING OR ANIMAL & 217 & $7.0 \%$ & 15 & 63.2 & 1.2 \\
\hline & A LIQUID OUTSIDE THE BODY & 38 & $1.2 \%$ & 6 & 3.7 & 2.4 \\
\hline 岩竹 & FIRE & 54 & $1.7 \%$ & 9 & 9.4 & 3.0 \\
\hline $\bar{n}^{0}$ & TOTAL & 401 & $12.9 \%$ & 37 & 280.3 & 1.6 \\
\hline & ILLNESS & 106 & $3.4 \%$ & 14 & 28.8 & 2.4 \\
\hline 望艺 & INSANITY & 21 & $0.7 \%$ & 4 & 1.6 & 3.4 \\
\hline نヨZ & TOTAL & 127 & $4.1 \%$ & 18 & 44.4 & 2.6 \\
\hline & A PHYSICAL OBJECT & 32 & $1.0 \%$ & 2 & 1.2 & 1.1 \\
\hline & A PIERCING OBJECT & 30 & $1.0 \%$ & 3 & 1.7 & 1.8 \\
\hline & A POSSESSION & 525 & $16.9 \%$ & 5 & 51.0 & 0.2 \\
\hline$\underset{⿱ 一}{\oplus}$ & FOOD & 16 & $0.5 \%$ & 2 & 0.6 & 2.3 \\
\hline z & AN OBSTACLE & 48 & $1.5 \%$ & 3 & 2.80 & 1.1 \\
\hline$\dot{\theta}$ & TOTAL & 651 & $21.0 \%$ & 15 & 189.6 & 0.4 \\
\hline & A PLACE OR CONTAINER & 36 & $1.2 \%$ & 4 & 1.0 & 1.3 \\
\hline 焉 & $\begin{array}{l}\text { SOMETHING THAT } \\
\text { SURROUNDS THE PERSON }\end{array}$ & 27 & $0.87 \%$ & 2 & 1.1 & 1.3 \\
\hline i & TOTAL & 27 & $0.87 \%$ & 6 & 2.8 & 2.7 \\
\hline
\end{tabular}

If we want to appreciate these differences, it is therefore not enough to look at a metaphor's frequency or its number of different linguistic expressions in isolation; rather these two parameters should be seen in relation to each other, because this tells us something about how productive a metaphor is and how creatively it is used. This is why I introduce two additional parameters that will be called productivity index and creativity ratio.

The productivity index is defined as the product of absolute subtype frequency (ASF) and number of different expressions (NDE). In order to give equal weight to both parameters, percentages are used rather than absolute 
figures. ${ }^{13}$ This operation provides us with an index that yields very high values for items that score high both on absolute subtype frequency and number of different expressions (for example FEAR IS LOCATED IN OR AFFECTS SPECIFIC BODY PARTS has a productivity index of 95.5), whereas metaphor subtypes with few different expressions and low frequency score very low (for example FEAR IS A PLANT with an index of 0.7).

The creativity ratio, on the other hand, is the ratio between the two parameters. ${ }^{14}$ This means that the higher the number of different expressions for a metaphor with respect to its overall frequency (i.e., the more creatively it is used), the higher the ratio will be. On the other hand, the more conventionalized a metaphor (with few, highly frequent, different expressions), the lower its score.

Table 4 shows the five quantitative indicators absolute subtype frequency (ASF), percentage of total metaphorical expressions, number of different expressions (NDE), productivity index (PI) and creativity ratio (CR) for all the metaphor subtypes explained in Section 4.1.1.

Looking at the parameters productivity index and creativity ratio, we can locate every metaphor on a cline from the most conventional to the most extravagant. Subdividing this continuum is to a certain extent subjective; nevertheless I want to give examples for each of three possible categories between which there are no clear-cut boundaries:

a) Highly conventional metaphors (CR is low or very low 1 , PI is high ${ }^{15}$, cf. Table 5)

These metaphors present high frequencies and a comparatively small number of different linguistic expressions. There can be a certain degree of variability in the words these metaphors are expressed through. However, they are characterised by a relatively small number of highly conventionalized fixed expressions.

b) Creatively used metaphors (CR is medium or high, PI is low to medium, cf. Table 6)

These metaphors have a relatively high number of different expressions combined with a medium to low frequency. The higher the creativity ratio, the more creatively a metaphor is used. This does not mean that individual

13. Productivity index: $\frac{A S F}{\text { total } A S F} * \frac{N D E}{\text { total } N D E}$

14. Creativity ratio (The absolute ratio is divided by its mean in order to normalize the result distributed around 1): $\frac{N D E}{A S F} / \frac{\phi \mathrm{NDE}}{\phi \mathrm{ASF}}$.

15. Applying the k-means clustering algorithm in order to take into account the clustering of the results, the values of $\mathrm{CR}$ and PI are distributed across five groups. PI below 5 is considered very low, 1 to 16 as low, 16 to 40 as medium, 40 to 75 as high, and above 75 as very high. A CR below 0.8 is rated as very low, 0.8 to 1.7 as low, 1.7 to 2.7 as medium, 2.7 to 4.2 as high, and above 4.2 as very high. 
Table 5. Highly conventional metaphors

\begin{tabular}{lllll}
\hline FEAR IS & ASF & NDE & PI & CR \\
\hline $\begin{array}{l}\text { SOMETHING THAT COMES FROM THE OUTSIDE } \\
\text { ( fill, inspire, instil(l), engender, fear-inspiring, fear-inducing) }\end{array}$ & 414 & 8 & 53.5 & 0.5 \\
$\begin{array}{l}\text { SOMETHING THE SELF FIGHTS BACK AGAINST } \\
\text { (conquer one's fear, overcome, fight, confront, override, }\end{array}$ & 345 & 7 & 46.9 & 0.4 \\
$\begin{array}{l}\text { combat, banish) } \\
\begin{array}{l}\text { A POSSESSION } \\
\text { (have, lose, bring, take, get rid of })\end{array}\end{array}$ & 525 & 5 & 51.0 & 0.2 \\
\hline
\end{tabular}

Table 6. Creatively used metaphors

\begin{tabular}{|c|c|c|c|c|}
\hline FEAR IS & ASF & NDE & PI & $\mathrm{CR}$ \\
\hline $\begin{array}{l}\text { FIRE } \\
\text { (spark, flash, fuel, stoke, flare, burn, extinguish, fire, ignite) }\end{array}$ & 54 & 9 & 9.4 & 3.0 \\
\hline $\begin{array}{l}\text { SOMETHING THAT IS DEEP INSIDE THE BODY WHEN } \\
\text { IT IS STRONG } \\
\text { (deep, deep-seated, deepen, ingrained, profound, deep-rooted, } \\
\text { entrenched) }\end{array}$ & 75 & 7 & 10.2 & 1.7 \\
\hline $\begin{array}{l}\text { ILLNESS } \\
\text { (develop, sick with, morbid, struck with fear, fear-stricken, } \\
\text { pathological, chronic, latent, infect, contagious, severe, stricken } \\
\text { with, fear-struck) }\end{array}$ & 106 & 14 & 28.8 & 2.4 \\
\hline $\begin{array}{l}\text { SOMETHING THAT DOMINATES } \\
\text { (take hold of, dominate, overtake, spur, overcome by, force, } \\
\text { fear-ridden, fear-driven, constrained by, inhibited by, take over, } \\
\text { succumb to, override, compel, driven) }\end{array}$ & 95 & 15 & 27.7 & 2.9 \\
\hline
\end{tabular}

Table 7. Rare metaphors

\begin{tabular}{lllll}
\hline FEAR IS & ASF & NDE & PI & CR \\
\hline $\begin{array}{l}\text { A LIQUID INSIDE THE BODY } \\
\text { (wave of fear (inside the person), trickle of fear, }\end{array}$ & 11 & 3 & 0.6 & 4.9 \\
fear drains from s/o) & & & & \\
\hline
\end{tabular}

metaphorical expressions have to be especially unusual, but rather that the conceptual metaphor is explored in a creative way in language use. Examples can be found in all of the four major metaphor types.

c) Rare metaphors (CR is high or very high, PI is very low, cf. Table 7) Rather infrequent metaphors are characterised by an extremely high creativity ratio and low productivity index. This is due to the combination of very low frequencies with a very small number of different expressions. 


\subsection{Evidence for conceptual metonymy}

As explained above (cf. Section 3.3.3), working with corpora does not really allow us to track conceptual metonymies. However, we do find a great number of expressions that evidence various physical effects of the emotion and it seems to be useful to analyse these co-occurrences in order to see which effects are most frequently used to describe in a graphic way the state of fear of a person. Table 8 shows quantitative data on the physical effects of fear as found in the corpus (for the complete details cf. Appendix 2).

Table 8. Physical effects of fear as evidenced in the corpus

\begin{tabular}{lrrrr}
\hline & ASF & NDE & PI & CR \\
\hline Fear causes agitation & 363 & 20 & 382.9 & 1.0 \\
Fear causes immobilisation or contraction & 179 & 13 & 122.7 & 1.3 \\
Fear causes body temperature to sink & 151 & 5 & 39.8 & 0.6 \\
Fear causes screaming or crying & 117 & 6 & 37.0 & 0.9 \\
Fear affects one's voice & 107 & 2 & 11.3 & 0.3 \\
Fear disturbs breathing & 87 & 9 & 41.3 & 1.9 \\
Fear shows in the face & 214 & 1 & 11.3 & 0.1 \\
Fear shows in the eyes & 380 & 14 & 280.6 & 0.7 \\
Fear causes dilation of the eyes & 80 & 6 & 25.3 & 1.4 \\
Fear causes an unpleasant taste or smell & 50 & 3 & 7.9 & 1.1 \\
Fear causes a change of colour & 41 & 5 & 10.8 & 2.2 \\
Fear causes weakness/incapability & 39 & 10 & 20.6 & 4.7 \\
Fear causes sweating & 31 & 3 & 4.9 & 1.8 \\
Fear causes a prickling sensation & 13 & 3 & 2.1 & 4.2 \\
Fear causes body temperature to rise & 7 & 2 & 0.7 & 5.2 \\
Fear causes loss of control over body functions & 2 & 1 & 0.1 & 9.0
\end{tabular}

From the point of view of frequency, agitation (with co-occurrences like tremble, shake, jump, etc.), immobilisation or contraction (paralyze, stiff, shrink, etc.) and falling body temperature (freeze, cold, icy, etc.) are the effects that are mentioned most often. If we also take into account the number of different expressions and calculate the productivity index and creativity ratio as explained in Section 4.1, we can distinguish three main groups:

a) Highly conventional conceptual metonymies (CR is low or very low, PI is high)

These are characterised by a low number of different expressions in relation to their frequency.

- Fear causes body temperature to sink: freeze, cold, etc.

- Fear shows in the eyes: eyes, look of fear, stare

b) Creatively used conceptual metonymies (CR is medium or high, PI is medium or low) 
- Fear causes a change of colour: white, tinge, pale, blanch, yellow

- Fear causes weakness: cripple, blind with, mute with, weak from, stumble, weak legs, disabling, speechless, debilitating, limp with

c) Rare conceptual metonymies (CR is high or very high, PI is very low)

- Fear causes body temperature to rise: ${ }^{16}$ hot, blaze

- Fear causes loss of control over body functions: ${ }^{17}$ wet oneself

\subsection{Conceptual proximity}

With respect to the conceptual proximity to other emotion words, 'fear' is most frequently found in combination with other negative emotions (in $85 \%$ of cases). ${ }^{18}$ The most frequent co-occurrences by far are those from the conceptual domain of "fear" itself $(26.4 \%)$. These can be grouped further into subdomains:

- Strong fear: fright, anguish, horror, dread, terror, panic

- Lack of trust: wariness, mistrust, distrust, suspicion

- Slight fear: worry, apprehension, concern

- Hopelessness: despair, desperation, anxiety

- Pathological forms of fear: phobia, paranoia

Other negative emotions include the following:

- negative emotions oriented towards others: anger (frustration, rage, disgust); hate (loathing, hatred, hostility); others (greed, envy, jealousy)

- insecurity (uncertainty, confusion, doubt)

- negative emotions oriented towards oneself (guilt, shame, remorse)

- sadness (grief, sorrow, hopelessness)

- pain (pain, hurt)

- inability to act (apathy, indecision, incapacity)

16. Another way of dealing with these "strange" examples is suggested by Kövecses (2005: 288-290). He introduces the concept of cognition over embodiment override to explain the apparent contradiction between the overall conceptual metonymy FEAR IS COLD and individual metaphors involving heat as an indicator of fear (like hot or blaze among our examples). This means that highly entrenched generic conceptual metaphors like INTENSITY IS HEAT can be applied even if the metaphor does not fit the embodied notion FEAR IS COLD.

17. The surprisingly low frequency of this metonymy is possibly due to the fact that the corpus was restricted to written genres of a rather formal kind (fiction, magazines, newspapers and academic papers).

18. The complete quantitative data can be found in appendix 3 . 
On the other hand, 'fear' is also found in combination with positive emotions, either feelings oriented towards others (love, respect) or feelings that are a reaction to good things in the present or future (hope, excitement, joy). Some of the co-occurring emotion words are ambivalent or neutral (pity, curiosity).

By themselves, perhaps these results do not tell us much more than what intuition might predict. However, in contrastive studies (interlinguistic or diachronic) this kind of analysis can be important to highlight differences between languages that are not plain to the eye if not backed by large quantities of corpus data. In a similar study that compares the German and Spanish words for the concept "pride" ('Stolz' and 'orgullo'), the analysis showed 'Stolz' to be more often found in the vicinity of the more positively oriented lexical units Selbstachtung (self-esteem) and Würde (dignity), whereas 'orgullo' was closer to vanidad (vanity), arrogancia (arrogance) and soberbia (haughtiness) (Oster 2010).

\subsection{Semantic preference and semantic prosody: Description and evaluation}

As happens with conceptual proximity, the results of an analysis of description and evaluation are appreciated best in a contrastive context, which will enable us to point out usage differences between languages. However, even in a monolingual study, looking more closely at the semantic fields of the collocates of 'fear' (semantic preference) and the data relating to evaluative expressions (semantic prosody) allows us to gain interesting insights into how the emotion is predominantly described and evaluated.

If we look at the semantic subsets that the co-occurrences belong to from the point of view of syntagmatic relations between the emotion concept and its surroundings in text, we will find information on causes of fear ("fear of sth."), on its objects ("fear for sth.") and on who experiences it (cf. Appendix 4). On closer look, the causes are related to punishment of some kind (retribution, retaliation), physical harm (death, injury), social consequences of one's acts (rejection, ridicule), persons or groups of persons (stranger, police), insecurity or violence (crime, war), natural things (night, heights), risks of modern life (weight gain, contamination), dangers in general (flying, risk), political, social or religious groupings (communism, immigrants) or dangers related to the economy (layoff, inflation). On the other hand, fear is experienced for a close relative (kid, husband) or for one's personal well-being (money, food). The experiencers can be classified into individuals in general (man, parent), members of specific groups (student, investor) or collective bodies (community, public).

Examination of the results also reminds us that corpus data always has to be handled with care and that, however big a corpus, it will only represent the reality of the texts it contains. In this case, the section of the COCA corpus 
used in the analysis reflects present-day American written language and even highlights some peculiarities of $20^{\text {th }}$ century American culture. For example, there are a striking number of references to the fear of liability, litigation, lawsuits or prosecution. Also, genre and/or subject matter can have an unexpected influence on the results when certain collocations acquire a term-like status and are used recurrently in specific publications. In this case, the rather unexpected frequency of gymnast as experiencer of fear and fear of victimization is almost exclusively due to their respective prolific use in the academic journals Sport Behavior and Adolescence.

With respect to descriptive and evaluative aspects of the emotion concept 'fear', it is probably not surprising that adjectives and to a lesser extent verbs proved to be the most revealing co-occurrences (cf. Appendix 5). From the point of view of description, intensity of the emotion is by far the most important aspect (35.5\% of the describing or evaluating items). These expressions refer to the size of the emotion (big, greatest, exaggerated), its being bad or dangerous (worst, terrible, dreadful), its strength (intense, strong, extreme) and, in a few cases, its weakness (faint, certain, slight). As to the quality of the emotion, there is a very large group of words that stress its being pure or real (real, genuine, naked, etc.). Another very frequent aspect is that of the origin of the emotion. In many cases, it is described as something that is not rational (irrational, instinctive, superstitious, etc.) or old (primal, innate, ancestral, etc.). Conversely, in very few cases $(0.3 \%)$ is it presented as rational. Other descriptive aspects refer to the duration of fear as long (constant, persistent, lifelong, etc.) its extension (pervasive, widespread, common) or its formlessness (vague, shapeless, unarticulated).

As to the analysis of evaluative co-occurrences, it proved useful to classify further the positive and negative evaluations into more differentiated aspects. This shows that the emotion is frequently presented as being either justified (well-founded, justify, healthy) or unjustified (unfounded, unreasonable, unwarranted). Only one - though very strong — collocation with a purely negative evaluation (abject) has been found. ${ }^{19}$ The most noticeable finding is probably that there is rather strong evidence $(12.4 \%$ of all descriptive or evaluative expressions) that fear is seen as something shameful (hide, betray, confess). This, again, is more interesting as contrastive data: results from a similar corpus-based study indicate that the same is true for Spanish but much less so for German (Oster 2008, 2010).

19. Kövecses (1998: 142) describes "positive - negative" evaluation of emotions through the use of certain metaphors. For example, an emotion that is seen as an illness is being conceptualized in a negative way, or happiness is evaluated positively through the metaphors HAPPINESS IS LIGHT / IS FEELING LIGHT / IS UP / IS BEING IN HEAVEN (Kövecses 2008b: 136). 


\section{Conclusions}

Corpus analysis has proved to be a powerful tool in many areas of linguistic research. With respect to the quantification of results, there have probably been more advances in areas like morphology or syntax, which are more easily formalized and quantified. There are also promising conceptual tools for semantic or pragmatic analyses (including collocation and co-occurrence, semantic prosody and semantic preference), but for these the methodological difficulty of finding an adequate balance between semi-automatic and manual analysis has to be overcome. Like in every semantic study, a "manual" analysis, that is a careful examination and classification of the examples, is necessary, but it is the corpus tools that make it possible to find the relevant stretches of text, process them efficiently, and thus keep the intervention of "intelligent" analysis at a manageable level.

What I have tried to do in this paper is to explore and explain a few of the possibilities, advantages and difficulties of corpus-based analyses of semantic and pragmatic aspects of language in one particular field, namely the linguistic expression of emotion concepts. The methodological procedure that has been proposed combines Kövecses' lexical approach and Stefanowitsch's metaphorical pattern analysis with additional concepts from corpus linguistics such as semantic preference and semantic prosody. In my view, such a corpus-based analysis of emotion words offers two advantages.

Firstly, by exploring the surroundings of the search word 'fear' in a truly vast amount of text and analysing the words it tends to co-occur with, we are not only able to find both evidence of conceptual metaphor and metonymy that structure the emotion concept and evidence of related emotion concepts, but also we have two other benefits. We can enrich the description of the emotion concept with information about a series of dimensions (intensity, quality, form, origin, duration and extension) and about the semantic subsets the cooccurrences typically belong to. We can also add a pragmatic viewpoint to the analysis by revealing an explicit or implicit evaluation of the emotion.

The second advantage offered by a corpus-based methodology lies in the possibility of quantifying results, i.e., comparing the frequency, productivity and creative use of individual metaphors and metonymies. Apart from taking into account the absolute and relative frequency of co-occurrences as well as the number of different expressions, the parameters productivity index and creativity ratio have been introduced as a tool for differentiating between different degrees of conventionality and creative use. Here we have seen that some highly frequent metaphors are expressed through a number of strongly conventionalized lexical items (this is the case of FEAR IS SOMETHING THAT COMES FROM THE OUTSIDE, for example) whereas others, although less frequent in absolute terms, are explored creatively by language users through a 
larger number of different linguistic expressions (FEAR IS FIRE or FEAR IS ILLNESS).

Being able to quantify the results in such a way is especially important with respect to interlinguistic contrastive studies. Due to intercultural exchange and mutual influence (in literature, philosophy, religion, science and film, for instance), which for many cultures and languages has been going on for thousands of years and is steadily increasing, languages have been continuously incorporating new features. It is highly probable that this is also the case for metaphorical systems. This may partly explain the high degree of coincidence in conceptual metaphors between languages and cultures (especially Western cultures) and even in individual metaphorical expressions. However, if we are able to look at quantitative results alongside qualitative data, this will give us a finer-grained picture and enable us to comprehend the subtler differences.

Received 4 August 2009

Universitat Jaume I

Revision received 8 April 2010

Appendix 1: Conceptual metaphors

\begin{tabular}{|c|c|}
\hline $\begin{array}{l}\text { A. } \rightarrow \text { FEAR IS } \\
\text { SOMETHING } \\
\text { INSIDE THE } \\
\text { BODY }\end{array}$ & $\begin{array}{l}\text { Something that is unspecifically located inside the body: fear in } \\
\ldots \text { persons, body [800], physical [94], body [63], fear moves } \\
\text { through .. [60], full of fear [45], fear inside [17], fear within [8], } \\
\text { harbor [14] } \\
\text { - Something that is located in or affects specific body parts: heart } \\
\text { [170], stomach [39], blood [38], chest [27], throat [9], visceral } \\
\text { [9], mouth [8], spine [7], vein [5], belly [4], muscles [3], neck [3], } \\
\text { nerves [2], lungs [2], skin [3] } \\
\text { - Something that affects the soul: soul [29] } \\
\text { - Something that comes from the outside: fill [114], strike, etc. fear } \\
\text { into ... [about 100], inspire [95], instill [65], engender [22], } \\
\text { fear-filled [6], fear-inspiring [5], fear-inducing [5], fear- } \\
\text { engendering [2] } \\
\text { - Something that is deep inside the body when it is strong: deep } \\
\text { [37], deep-seated [16], deepen [6], ingrained [5], profound [5], } \\
\text { deep-rooted [4], entrenched [2] } \\
\text { - Something that tends to go up in the body when it becomes } \\
\text { stronger: rise in/inside s/o [40], swallow [11], force down one's } \\
\text { fear [4], gulp back/down [4], escalating [3] } \\
\text { - A liquid inside the body: wave of fear [5], trickle of fear [4], fear } \\
\text { drains from s/o [2], ebb [4] } \\
\text { Something that emanates from the body and is thus perceptible: } \\
\text { smell [45], fear-scent [2] }\end{array}$ \\
\hline
\end{tabular}




\section{Appendix 1 (Continued)}

\begin{tabular}{|c|c|}
\hline $\begin{array}{l}\text { B i. } \rightarrow \text { FEAR IS } \\
\text { AN ANTAGONIST }\end{array}$ & $\begin{array}{l}\text { - An attacker: grip [60], overwhelm [39], seize [34], clutch [10], } \\
\text { escape fear [8], plagued by fear [5], stab [4], fear-gripped [2] } \\
\text { - Something that dominates: dominate [15], overtake [14], spur } \\
\text { [12], overcome by [10], take hold of [9], fear forces [8], fear- } \\
\text { ridden [5], under fear [5], fear-driven [4], constrained by fear [2], } \\
\text { inhibited by fear [3], fear takes over [2], succumb to [3], fear } \\
\text { overrides [3], compel [3], driven by [2] } \\
\text { - A burden: outweigh [13], carry [12], alleviate [12], weight [10], } \\
\text { fraught with [4], heavy [4], fear-charged [2], fear-laden [2] } \\
\text { - Something that destroys: consume [17], nagging [12], fear eats } \\
\text { s/o [12], gnawing [5], all-consuming [4] } \\
\text { - Something the self fights back against: overcome [203], conquer } \\
\text { one's fear [61], fight back [50], confront [20], override [3], } \\
\text { combat [6], fear banished [2] } \\
\text { - Something that inflicts pain: suffer [22], twinge [5], numb one's } \\
\text { fear [3], tortured by fear [3] } \\
\text { - An evil force: haunt [37], possessed by [4], demon [4] } \\
\text { Darkness: dark [12], shadow [7] }\end{array}$ \\
\hline $\begin{array}{l}\text { B ii. } \rightarrow \text { FEAR IS } \\
\text { AN } \\
\text { AUTONOMOUS } \\
\text { FORCE }\end{array}$ & $\begin{array}{l}\text { An unspecific autonomous force: spread [50], fear sweeps [10], } \\
\text { uncontrollable [9], powerful [6], recede [5] } \\
\text { - A plant: sow [13], deep-rooted [4] } \\
\text { A human being or animal: grow [63], arouse fear [30], lurk [28], } \\
\text { engender [22], awaken [13], breed fear [10], born of fear [9], } \\
\text { lurking [9], stir [8], fear-arousing [3], beget fear [2], creep [26], } \\
\text { wild [6], fear feeds on sth. [5], crawl [3], fear-engendering [2] } \\
\text { - A liquid outside the body: wave of fear [20], fear washes over s/o } \\
\text { [6], evaporate [5], ebb [4], undercurrent of fear [3] } \\
\text { - Fire: spark [14], flash [10], fuel [7], stoke [7], flare [4], burn [4], } \\
\text { extinguish [3], fire [3], ignite [2] }\end{array}$ \\
\hline $\begin{array}{l}\mathrm{C} \rightarrow \text { FEAR IS AN } \\
\text { ILLNESS/ } \\
\text { INSANITIY }\end{array}$ & $\begin{array}{l}\text { Illness: develop a fear [30], sick with [10], morbid [10], struck } \\
\text { with fear [10], fear-stricken [5], pathological [8], chronic [7], } \\
\text { latent [6], infect [5], contagious [4], severe [4], stricken with [2], } \\
\text { fear-struck [2], epidemic [3] } \\
\text { Insanity: crazy with fear [9], mad with [5], fear-crazed [4], insane } \\
\text { with/from [3] }\end{array}$ \\
\hline $\begin{array}{l}\mathrm{D} \rightarrow \text { FEAR IS AN } \\
\text { OBJECT }\end{array}$ & $\begin{array}{l}\text { - A physical object: palpable [17], push away [15], } \\
\text { - A piercing object: edge [20], acute [6], sharp [4] } \\
\text { - A possession: have [287], lose [150], bring [60], take one's fear } \\
\text { [20], get rid of [8] } \\
\text { - Food: feed on fear [15], to be fed fear } \\
\text { - An obstacle: get over one's fear [10], get past one's fear [7], } \\
\text { move, shove, etc. past one's fear [5], break through fear [2] }\end{array}$ \\
\hline $\begin{array}{l}\mathrm{E} \rightarrow \text { FEAR IS A } \\
\text { PLACE/ } \\
\text { CONTAINER }\end{array}$ & $\begin{array}{l}\text { - A place or container: in one's fear [about 1000], out of fear } \\
\text { [about 400], verb of movement (sink, plunge, etc.) into fear [6], } \\
\text { beyond fear [18], verb of movement (move, push, etc.) toward [3] } \\
\text { - Something that surrounds people: push, move, etc. through one's } \\
\text { fear [25], amid fear [5], thick in the air [2] }\end{array}$ \\
\hline
\end{tabular}


Appendix 2: Conceptual metonymies

\begin{tabular}{|c|c|}
\hline Fear causes agitation & $\begin{array}{l}\text { tremble [110], shake [82], shiver of fear [39], thrill [22], } \\
\text { jump [18], quiver [15], trepidation [14], quake [12], tremor } \\
\text { [12], shudder [9], frisson [5], knee-jerk [4], jolt of fear [4], } \\
\text { frantic with fear [4], heart leaps [3], jittery [2], frenzied [2], } \\
\text { flicker of fear [2], ripple of fear [2], shaky [2] }\end{array}$ \\
\hline $\begin{array}{l}\text { Fear causes immobilisation } \\
\text { or contraction }\end{array}$ & $\begin{array}{l}\text { paralyze [101], cower [19], stiff [12], shrink [11], rigid [8], } \\
\text { immobilize [6], cringe [6], petrified [5], taut with [2], } \\
\text { heart-stopping [2], immobility [2], tense with [2], curdle [3] }\end{array}$ \\
\hline $\begin{array}{l}\text { Fear causes the } \\
\text { temperature to sink }\end{array}$ & freeze [76], cold [42], chill [26], icy [5], ice [2] \\
\hline $\begin{array}{l}\text { Fear causes screaming or } \\
\text { crying }\end{array}$ & $\begin{array}{l}\text { scream [35], cry [32], tear [31], howl [7], sob [7], whimper } \\
\text { [6] }\end{array}$ \\
\hline Fear affects the voice & voice [105], shrill [2] \\
\hline Fear disturbs breathing & $\begin{array}{l}\text { take a quick breath [26], breathy voice [2], breathe hard/fast } \\
\text { etc. [18], choke [16], gasp [13], lump of fear in chest/ } \\
\text { stomach/throat [5], knot of fear [3], suffocating [2], } \\
\text { breathless [2] }\end{array}$ \\
\hline Fear shows in the face & $\begin{array}{l}\text { - It shows in the face: in/on face [180], mouth [20], twisted } \\
\text { face [8], contorted [8] } \\
\text { - It shows in the eyes/way of looking: eye [334], look of } \\
\text { fear [32], stare [14] } \\
\text { - It causes dilation of the eyes: wide with fear [42], } \\
\text { wide-eyed [11], eyes widen [16], dilate [4], wide-eyed } \\
\text { [5], fear-widened [2] }\end{array}$ \\
\hline $\begin{array}{l}\text { Fear causes a change of } \\
\text { colour }\end{array}$ & $\begin{array}{l}\text { white with fear [15], tinge [11], pale [7], blanch [6], yellow } \\
\text { [2] }\end{array}$ \\
\hline $\begin{array}{l}\text { Fear causes an unpleasant } \\
\text { taste or smell }\end{array}$ & smell [45], taste [3], sour [2] \\
\hline $\begin{array}{l}\text { Fear causes weakness/ } \\
\text { incapability }\end{array}$ & $\begin{array}{l}\text { cripple [15], blind with [4], mute with [4], weak from [4], } \\
\text { stumble [2], make legs weak [2], disabling [2], speechless } \\
\text { [2], debilitating [2], limp with [2] }\end{array}$ \\
\hline Fear causes sweating & sweat [21], clammy [6], fear-sweat [4] \\
\hline $\begin{array}{l}\text { Fear causes the } \\
\text { temperature to rise }\end{array}$ & hot [4], blaze [3] \\
\hline $\begin{array}{l}\text { Fear causes a prickling } \\
\text { sensation }\end{array}$ & prickle [9], spine-tingling [2], tingle [7] \\
\hline $\begin{array}{l}\text { Fear causes loss of control } \\
\text { over body functionsbladder } 1 \\
\text { bowels }\end{array}$ & wet oneself [2] \\
\hline
\end{tabular}




\section{Appendix 3: Conceptual proximity}

\begin{tabular}{|c|c|}
\hline $\begin{array}{l}\text { Negative } \\
\text { emotions }\end{array}$ & $\begin{array}{l}\text { fear: anxiety [248], panic [108], terror [73], concern [69], suspicion [60], } \\
\text { dread [50], distrust [46], apprehension [45], horror [42], despair [39], } \\
\text { mistrust [39], worry [29], desperation [28], paranoia [27], phobia [19], } \\
\text { anguish [16], fright [8], wariness [4] } \\
\text { - negative emotions oriented towards others: } \\
\text { - anger: anger [380], frustration [67], rage [60], disgust [40], resentment } \\
\text { [39], fury [23], bitterness [16], wrath [15], irritability [5] } \\
\text { - hate: loathing [102], hatred [99], hate [66], hostility [25], revulsion } \\
\text { [21], antipathy [6], repulsion [5], repugnance [2], detestation [2] } \\
\text { - others: greed [55], envy [32], jealousy [17] } \\
\text { insecurity: uncertainty [82], confusion [104], insecurity [54], doubt [48], } \\
\text { helplessness [25], shyness [11], bewilderment [9], self-doubt [6], } \\
\text { disorientation [5], timidity [4] } \\
\text { - negative emotions oriented towards oneself: guilt [127], shame [95], } \\
\text { remorse [9], self-pity [5], self-blame [3] } \\
\text { - sadness: sadness [77], grief [61], sorrow [41], hopelessness [11], dejection } \\
\text { [2], aloneness [2], homesickness [2] } \\
\text { - pain: pain [225], hurt [7] } \\
\text { inability to act: apathy [9], indecision [5], weariness [5], incapacity [2] }\end{array}$ \\
\hline $\begin{array}{l}\text { Positive } \\
\text { emotions }\end{array}$ & $\begin{array}{l}\text { - positive emotions oriented towards others: love [97], awe [48], respect } \\
\text { [4], reverential [2] } \\
\text { positive feelings as a reaction to good things in the present or future: hope } \\
\text { [80], excitement [63], joy [54], pleasure [37], relief [35], euphoria [7], } \\
\text { elation [6], exhilaration [6], gladness [3] }\end{array}$ \\
\hline $\begin{array}{l}\text { Ambivalent } \\
\text { or neutral } \\
\text { emotions }\end{array}$ & - desire [72], pity [60], passion [23], curiosity [6] \\
\hline
\end{tabular}

\section{Appendix 4: Semantic subsets of the co-occurrences}

\begin{tabular}{|c|c|}
\hline Causes "fear of" & $\begin{array}{l}\text { Punishment of some kind: retribution [51], retaliation [48], } \\
\text { punishment [42], reprisal [70], repression [5], repercussion [13] } \\
\text { litigation [21], persecution [38], prosecution [32], lawsuit [25], } \\
\text { intervention [15], liability [19], damnation [7], deportation [15], } \\
\text { recrimination [3], annihilation [3], lawsuit [23], discovery [21], arrest } \\
\text { [18], entrapment [5] } \\
\text { - Physical harm: death [268], injury [61], harm [53], disease [23], } \\
\text { cancer [37], doctor [3], pregnancy [8], illness [15], castration [11], } \\
\text { contagion [9], sterility [5], insanity [3], blindness [5], germ [5], } \\
\text { epidemic [4], flu [4], needle [12], AIDS [33], } \\
\text { - Social consequences of one's acts: rejection [59], victimization [68], } \\
\text { humiliation [9], isolation [2], abandonment [24], exposure [18], } \\
\text { censure [6], stigma [13], ridicule [13], censorship [6], discrimination } \\
\text { [14], scandal [10], exclusion [4] }\end{array}$ \\
\hline
\end{tabular}




\section{Appendix 4 (Continued)}

\begin{tabular}{|c|c|}
\hline & $\begin{array}{l}\text { - A person or group of persons: mother [3], man [25], stranger [18], } \\
\text { husband [3], enemy [6], name [8], teacher [4], blacks [4], foreigner } \\
\text { [8], thief [3], witch [4], police [9], } \\
\text { - Insecurity or violence: crime [194], violence [122], war [102], abuse } \\
\text { [7], conflict [10], gun [5], anarchy [7], unrest [4], terrorism [30], } \\
\text { harassment [8], aggression [5], casualty [8], assassination [4], gang } \\
\text { [4], chaos [18], } \\
\text { - } \quad \text { Natural things: night [14], heights [68], darkness [6], nature [5], } \\
\text { snake [24], dark [31], dog [25], fire [16], spider [12], Unavoidable } \\
\text { dangers: future [55], loss [102], } \\
\text { - Risks of modern life: weight gain [22], food [10], technology [18], } \\
\text { success [37], contamination [10] } \\
\text { - Dangers: danger [39], risk [9], drowning [10], flying [72], airplane } \\
\text { - } 4 \text { Personal inadequacies: mistake [18], failure [240], } \\
\text { - Political, social or religious groupings: communism [19], immigrant } \\
\text { [12], fundamentalism [5], Islam [5] } \\
\text { Dangers related to the economy: layoff [8], unemployment [12], } \\
\text { inflation [8] }\end{array}$ \\
\hline Experiencer & $\begin{array}{l}\text { - Individuals in general: man [90], child [80], woman [85], parent } \\
\text { [55], mother [6], father [21], kid [15], boy [32], girl [29], victim [18], } \\
\text { Member of a specific group: American [40], officials [30], student } \\
\text { [30], blacks [2], voter [12], gymnast [10], opponent [8], prisoner [5], } \\
\text { teacher [5], politician [8], worker [15], leader [15], soldier [18], } \\
\text { investor [15], patient [15], } \\
\text { - Groups: community [25], public [32], population [22], nation [21], } \\
\text { family [21] }\end{array}$ \\
\hline Object "fear for" & $\begin{array}{l}\text { - A close relative: kid [5], husband [5], son [8], baby [17], wife [3] } \\
\text { - Personal well-being: money [13], food [2], safety [46], health [9], }\end{array}$ \\
\hline
\end{tabular}

Appendix 5: Descriptive and evaluative aspects

\begin{tabular}{|l|l|}
\hline \multicolumn{2}{|l|}{ Description } \\
\hline \multicolumn{2}{|l|}{ Intensity } \\
\hline - big & $\begin{array}{l}\text { big [151], greatest [127], great [112], exaggerated [13], inordinate [12], } \\
\text { enormous [6], excessive [6], ultimate [6], absolute [5], overblown [4], huge } \\
\text { [4], outsized [2], preternatural [2] }\end{array}$ \\
\hline $\begin{array}{l}\text { - bad/ } \\
\text { dangerous }\end{array}$ & $\begin{array}{l}\text { worst [88], terrible [26], tremendous [15], horrible [11], dreadful [10], awful } \\
\text { [6], dark [6], bad [5] }\end{array}$ \\
\hline - strong & intense [29], strong [29], extreme [19], stark [6] \\
\hline - weak & certain [14], faint [10], slight [8], small [4], quiet [4], gentle [2], mild [2] \\
\hline
\end{tabular}




\section{Appendix 5 (Continued)}

\begin{tabular}{|c|c|}
\hline \multicolumn{2}{|l|}{ Quality: } \\
\hline - pure & $\begin{array}{l}\text { real [108], genuine [22], pure [14], naked [8], raw [8], outright [5], sheer [7], } \\
\text { utter [5], plain [3], plain [2] }\end{array}$ \\
\hline \multicolumn{2}{|l|}{ Form: } \\
\hline - vague & vague [6], formless [4], shapeless [2], dull [4], unarticulated [2] \\
\hline \multicolumn{2}{|l|}{ Origin: } \\
\hline - not rational & $\begin{array}{l}\text { irrational [58], instinctive [12], superstitious [9], unreasoning [7], } \\
\text { subconscious [5], instinctual [5] }\end{array}$ \\
\hline $\begin{array}{l}\text { - very old/ } \\
\text { innate }\end{array}$ & primal [41], innate [10], primitive [8], atavistic [4], ancestral [4], inborn [3] \\
\hline - rational & rational [5] \\
\hline \multicolumn{2}{|l|}{ Duration: } \\
\hline - long & $\begin{array}{l}\text { constant [94], always [51], persistent [19], ever-present [11], lifelong [10], } \\
\text { abiding [9], perpetual [8], long-standing [5], eternal [3] }\end{array}$ \\
\hline \multicolumn{2}{|l|}{ Extension: } \\
\hline - widespread & $\begin{array}{l}\text { pervasive [34], widespread [36], common [28], generalized [13], spreading } \\
\text { [8] }\end{array}$ \\
\hline \multicolumn{2}{|l|}{ Evaluation: } \\
\hline $\begin{array}{l}\text { - positive: } \\
\text { justified }\end{array}$ & $\begin{array}{l}\text { well-founded [26], justify [19], healthy [18], understandable [9], realistic } \\
\text { [9], justified [8], legitimate [2] }\end{array}$ \\
\hline - negative & abject [15] \\
\hline $\begin{array}{l}\text { - negative: } \\
\text { unjustified }\end{array}$ & $\begin{array}{l}\text { unfounded [19], unreasonable [9], unwarranted [8], inexplicable [6], } \\
\text { unrealistic [6], childish [4], ungrounded [4] }\end{array}$ \\
\hline $\begin{array}{l}\text { - negative: } \\
\text { shameful }\end{array}$ & $\begin{array}{l}\text { hide [61], acknowledge [22], betray [22], confess [18], suppressed [15], } \\
\text { admit [15], secret [12], conceal [11], mask [11], unspoken [10], cover [10], } \\
\text { hidden [4], bespeak [2] }\end{array}$ \\
\hline
\end{tabular}

\section{References}

Bednarek, Monika. 2008a. Emotion Talk across Corpora. Houndmills: palgrave Macmillan. Bednarek, Monika. 2008b. Semantic preference and semantic prosody re-examined. Corpus Linguistics and Linguistic Theory. 4(2), 119-139. 
Channell, Joanna. 2000. Corpus-Based Analysis of Evaluative Lexis. In Hunston, Susan and Geoff Thompson (eds.), Evaluation in Text. Authorial Stance and the Construction of Discourse, 3855. Oxford: Oxford University Press.

Charteris-Black, Jonathan. 2004. Corpus Approaches to Critical Metaphor Analysis. Houndmills: Palgrave Macmillan.

Davies, Mark. 2008-. The Corpus of Contemporary American English (COCA). Available online at: http://www.americancorpus.org/.

Deignan, Alice. 2005. Metaphor and Corpus Linguistics. Amsterdam: John Benjamins.

Deignan, Alice. 1999. Corpus-based research into metaphor. In Cameron, Lynne \& Graham Low (eds.), Researching and Applying Metaphor, 177-199. Cambridge: Cambridge University Press.

Fussell, Susan R. (ed.). 2002. The Verbal Communication of Emotions: Interdisciplinary Perspectives. Mahwah, New Jersey: Lawrence Erlbaum.

Fussell, Susan R. and Mallie M. Moss. 1998. Figurative language in emotional communication. In Fussell, Susan R. and Roger J. Kreuz (eds.), Social and Cognitive Aspects of Interpersonal Communication, 113-143. Mahwah, New Jersey: Lawrence Erlbaum.

Gevaert, Caroline. 2001. Anger in Old and Middle English: A 'Hot' Topic? Belgian Essays on Language and Literature. 89-101.

Gevaert, Caroline. 2005. The ANGER IS HEAT Question: Detecting Cultural Influence on the Conceptualization of Anger through Diachronic Corpus Analysis. In Delbecque, Nicole, Johan van der Auwera and Dirk Geeraerts (eds.), Perspectives on Variation: Sociolinguistic, Historical, Comparative, 195-208. Berlin and New York: Mouton de Gruyter.

Hoey, Michael. 2005. Lexical Priming. A new theory of words and language. London and New York: Routledge.

Hunston, Susan. 2007. Semantic prosody revisited. International Journal of Corpus Linguistics. 12(2), 249-268.

Koller, Veronika. 2006. Of critical importance: Using electronic text corpora to study metaphor in business media discourse. In Stefanowitsch, Anatol and Stefan Th. Gries (eds.), Corpus-Based Approaches to Metaphor and Metonymy, 237-266. Berlin, New York: Mouton de Gruyter.

Koller, Veronika. 2008. Brothers in arms. Contradictory metaphors in contemporary marketing discourse. In Cameron, Lynne, Mara Sophia Zanotto and Marilda C. Cavalcanti (eds.), Confronting Metaphor in Use: an applied linguistic approach, 103-126. Amsterdam and Philadelphia: John Benjamins.

Kövecses, Zoltán. 1986. Metaphors of Anger, Pride, and Love: A Lexical Approach to the Structure of Concepts. Amsterdam: John Benjamins.

Kövecses, Zoltán. 1990. Emotion Concepts. New York: Springer-Verlag.

Kövecses, Zoltán. 1998. Are there any emotion-specific metaphors? In Athanasiadou, Angeliki and Elzbieta Tabakowska (eds.), Speaking of Emotions. Conceptualization and Expression, 127151. Berlin and New York: Mouton de Gruyter.

Kövecses, Zoltán. 2000. Metaphor and Emotion: Language, Culture, and Body in Human Feeling. Cambridge: Cambridge University Press.

Kövecses, Zoltán. 2005. Metaphor in Culture. Universality and Variation. Cambridge: Cambridge University Press.

Kövecses, Zoltán. 2008a. Conceptual metaphor theory: Some criticisms and alternative proposals. Annual Review of Cognitive Linguistics. 6, 168-184.

Kövecses, Zoltán. 2008b. The Conceptual Structure of Happiness. In Tissari, Heli, Anne Birgitta Pessi and Mikko Salmela (eds.), Happiness: Cognition, Experience, Language, 131-143. Helsinki: Helsinki Collegium for Advanced Studies.

Louw, Bill. 1993. Irony in the Text or Insincerity in the Writer? The Diagnostic Potential of Semantic Prosodies. In Baker, Mona, Gill Francis and Elena Tognini-Bonelli (eds.), Text 
and Technology: In Honour of John Sinclair, 240-251. Amsterdam and Philadelphia: Benjamins.

Morley, John and Alan Partington. 2009. A few Frequently Asked Questions about semantic-or evaluative - prosody. International Journal of Corpus Linguistics. 14(2), 139-158.

Munday, Jeremy. in press. 'Looming large: A cross-linguistic analysis of semantic prosodies in comparable reference corpora'. In Kruger, Alet and Kim Walmach (eds.), Corpus-Based Translation Studies. Manchester: St. Jerome.

Oster, Ulrike. 2008. "Angst" and "fear" in contrast: A corpus-based analysis of emotion concepts. Paper presented at the International Conference on Cognitive Linguistics between Universality and Variation, Dubrovnik, 30 September-1 October.

Oster, Ulrike. 2010. Metáforas conceptuales y emociones: El análisis de corpus como herramienta de la enseñanza de la traducción. In Emsel, Martina and Annette Endruschat (eds.), La metáfora en la traducción, 153-172. München: Martin Meidenbauer.

Pragglejaz, Group. 2007. MIP: A method for identifying metaphorically used words in discourse. Metaphor and Symbol. 22(1), 1-39.

Schwarz-Friesel, Monika. 2007. Sprache und Emotion. Tübingen and Basel: A. Francke.

Sinclair, John. 1987. Collocation: a progress report. In Steele, Ross and Terry Threadgold (eds.), Language Topics. Essays in Honour of Michael Halliday, 319-332. Amsterdam and Philadelphia: Benjamins.

Sinclair, John. 1996. The Search for Units of Meaning. TEXTUS. IX(1), 75-106.

Stefanowitsch, Anatol. 2005. The function of metaphor: Developing a corpus-based perspective. International Journal of Corpus Linguistics. 10(2), 161-198.

Stefanowitsch, Anatol and Stefan Thomas Gries (eds.) 2006. Corpus-based Approaches to Metaphor and Metonymy. Berlin: Mouton de Gruyter.

Stefanowitsch, Anatol. 2006. Words and their metaphors: A corpus-based approach. In Stefanowitsch, Anatol \& Stefan Thomas Gries (eds.), Corpus-Based Approaches to Metaphor and Metonymy, 63-105. Berlin / New York: Mouton de Gruyter.

Stewart, Dominic. 2009. Safeguarding the lexicogrammatical environment: Translating semantic prosody. In Beeby, Allison, Patricia Inés Rodríguez and Pilar Sánchez-Gijón (eds.), Corpus Use and Translating: Corpus use for learning to translate and learning corpus use to translate, 29-46. Amsterdam: Benjamins.

Stubbs, Michael. 1995. Collocations and semantic profiles. On the cause of the trouble with quantitative studies. Functions of Language. 2(1), 23-55.

Stubbs, Michael. 2001. Words and Phrases. Corpus Studies of Lexical Semantics. Oxford: Blackwell.

Stubbs, Michael. 2002. Words and Phrases. Corpus Studies of Lexical Semantics. Oxford: Blackwell.

Tognini-Bonelli, Elena. 2001. Corpus linguistics at work. Amsterdam: John Benjamins.

Whitsitt, Sam. 2005. A critique of the concept of semantic prosody. International Journal of Corpus Linguistics. 10, 283-305.

Wierzbicka, Anna. 1990. The semantics of emotion: fear and its relatives in English. Australian Journal of Linguistics (Special issue on the semantics of emotions). 10(2), 395-375.

Wierzbicka, Anna. 1992a. Defining emotion concepts. Cognitive Science. 16, 539-81.

Wierzbicka, Anna. 1992b. Semantics, Culture and Cognition: Universal human concepts in culture-specific configurations. New York: Oxford University Press.

Wierzbicka, Anna. 1999. Emotions across Languages and Cultures. Cambridge: Cambridge University Press.

Wilce, James M. 2009. Language and Emotion. Cambridge: Cambridge University Press.

Xiao, Richard \& Tony McEnery. 2006. Collocation, Semantic Prosody and Near Synonymy: A Cross-Linguistic Perspective. Applied Linguistics. 27(1), 103-129. 
